\title{
Exploring Children's Requirements for Game-Based Learning Environments
}

\author{
Tuula Nousiainen $^{1}$ and Marja Kankaanranta ${ }^{1,2}$ \\ ${ }^{1}$ Agora Center, University of Jyväskylä, P.O. Box 35, 40014 Jyväskylä, Finland \\ ${ }^{2}$ Institute for Educational Research, University of Jyväskylä, P.O. Box 35, 40014 Jyväskylä, Finland \\ Correspondence should be addressed to Tuula Nousiainen, tuula.nousiainen@jyu.fi
}

Received 8 October 2007; Revised 21 April 2008; Accepted 24 July 2008

Recommended by Adrian Cheok

End users' expertise in the development of new applications is acknowledged in user-centered and participatory design. Similarly, children's experience of what they find enjoyable and how they learn is a valuable source of inspiration for the design of products intended for them. In this paper, we explore experiences obtained from collaboration with elementary school children in the design of learning environments, based on three projects and three requirements gathering techniques. We also discuss how the children experienced the participation. The children's contribution yielded useful, both expected and unanticipated, outcomes in regard to the user interface and contents of the learning environments under development. Moreover, we present issues related to design collaboration with children, especially in terms of the children's feeling of ownership over the final outcome.

Copyright (C) 2008 T. Nousiainen and M. Kankaanranta. This is an open access article distributed under the Creative Commons Attribution License, which permits unrestricted use, distribution, and reproduction in any medium, provided the original work is properly cited.

\section{Introduction}

The potential of involving children as active contributors in technology design is being increasingly acknowledged (e.g., [1-3]). Children are no longer seen only as research objects or as a passive target group for the development of new technologies. Instead, similarly as the end users' knowledge about, for example, their work practices is valued in participatory design with adults (e.g., [4]), also children's expertise about the issues they are familiar with is considered valuable. Several researchers (e.g., $[5,6])$ have emphasized the need to better understand children's needs as technology users as their ways of interacting with technology often differ fundamentally from those of adults, for example, in terms of curiosity and tendency to explore, and their preference of working together. Moreover, children's wishes especially regarding the fun and motivating aspects may be difficult for adult designers to envision $[3,6]$. A recently emerged perspective to designing applications for children is childcomputer interaction (CCI), which applies HCI principles and participatory methods to this specific context (e.g., [6]). Moreover, the design of educational software has broadened the HCI perspective to bring in principles of pedagogical design: an approach referred to as learner-centered design (LCD) has been introduced as a way of bringing together $\mathrm{HCI}$ on the one hand and educational and developmental principles on the other $[7,8]$. Additionally, it is worth looking into areas such as child-centered pedagogy and sociology for a multidisciplinary perspective on children's active citizenship and empowerment (e.g., $[9,10])$.

Traditional user-centered design has been criticized for placing the users in the role of mere reactors to suggested solutions, not initiators of ideas (e.g., $[11,12])$. In other words, the users' contribution is minimal—or left out altogether-in all other design phases except for the testing and evaluation of solutions in different iterations. To respond to this concern, researchers have developed and applied various requirements gathering techniques aiming to allow the users to initiate ideas early in the design process. As an alternative for traditional interviewing in the gathering of early requirements, for example, several studies have employed techniques specifically tailored to children. These include, for example, photo diaries [13], Kid Reporter in which children create "newspaper articles" related to the themes of the application [14], and "Mission from Mars" entailing an innovative interview technique and enhanced 
with photo collage creation $[15,16]$. Moreover, more specific ideas for the functions and the appearance of the application being developed have been explored through different creative techniques based on drawings [3, 17], storyboarding $[18,19]$, and collaborative low-tech prototype creation $[1,20,21]$.

Gathering ideas from children early in the design process has yielded useful insights into what children want in technology in general or in a specific type of application. Druin et al. [21], for example, discovered that children want especially control, variety, social interaction, and creative tools, and that they pay attention to the appearance, learnability, and "coolness" of an application, as well as to how rich it is in terms of the use of multimedia. Children's early involvement in requirements gathering has revealed clues also about, for example, gender differences in preferences related to technology, children's navigation skills, ways of presenting textual information, application-specific contentrelated preferences, the variety of elements to be included in user interfaces and their structures, and children's desire to personalize their applications [14, 15, 17-19].

The aims of the study presented in this paper were twofold. Firstly, the goal was to develop game-based learning environments that would respond to children's requirements, and secondly, the goal was to analyze the development process from the perspectives of both the developers and the children. This paper focuses on examining the significance of children's participation for the collaborative technology design process and for the attributes of the products. A specific feature was to carry out the design project in authentic school environments, which required the development of collaborative school-based methods for child-centered design. We address issues yielded by three idea gathering practices that were used in the projects, namely, user interface drawings, idea map creation, and the evaluation of existing learning environments.

\section{Research Process}

The principal research approach in our study was development research. It is employed in studies of educational interventions, addressing either the intervention itself, the process of developing it, or both [22, 23]. Using the principles of development research and case study research [24], we have studied the development processes of three game-based learning environments or websites for children. The three applications discussed in this paper are Talarius, Virtual Peatland, and Kids' Site (Child Ombudsman's website for children).

Talarius is a software tool with which children can create and play educational computer board games. Working in pairs or small groups, the children gather material relevant to the topic of their game (factual texts, images, sounds, videos). Based on this material, they create questions, design a game board, and play games created by their classmates. This paper deals with the development of the pilot version of the application, which took place in the academic year 20032004. A school class (23 children, ages 11-12) participated in the project from the requirements collection to the evaluation of the final outcome.

Virtual Peatland is a web-based learning environment about peatlands. It includes text-based information sections as well as interactive and game-like parts (Peatland Adventure game and various quizzes). In the years 2005 and 2006, an elementary school class (approximately 25 children at a time, ages 11-12) participated in the process through various workshop sessions, each of which dealt with a specific aspect related to the structure of the learning environment or presentation forms to be used in it.

Kids' Site is a part of the Finnish Child Ombudsman's website, aiming to make children aware of the UN Convention on the Rights of the Child, to enable them to have a say in issues concerning them, and to share stories about their everyday lives. A group of 7-9-year-old children from an after-school care facility took part in the project at different stages in the years 2006 and 2007. The group size varied from four to eight children between sessions. Additionally, a brief paper questionnaire about ideas related to the website was answered by 25 children.

In each case, the data consisted of development documents, outcomes of the design processes, interviews and questionnaires to the developers and the child participants, and observation of the design process documented in research journals. Experiences related to the development process were gathered both from the perspective of the children and that of the developers. The data was analyzed using a framework consisting of several research questions as a basis of analysis. In terms of this paper, from the children's point of view, the research questions were principally related to whether they felt that their ideas had had an effect on the final outcome, how they perceived their own expertise in the project, and how they experienced the participation activities in general. From the developers' perspective, it was examined how they felt the children's participation and ideas aided their work and affected their development solutions. Additionally, design session outcomes were compared to the final products in order to examine how the ideas provided by the children manifested in the final applications.

\section{What Children Want in Game-Based Learning Environments}

Several different idea gathering techniques and practices were used in the course of the projects. In this paper, we address three of them, namely, user interface (UI) drawings, idea maps, and evaluations of existing learning environments, presenting issues discovered through these activities and how they guided the development of the applications. They represent different approaches to idea generation: the drawings start from scratch and leave plenty of room for imagination, the idea maps entail collaborative and gradual development of ideas, and the evaluation of learning environments provides a collection of different existing solutions to draw upon. Additional ideas and feedback were obtained through prototype evaluation and field trials, but in this 
paper we focus on ideas obtained before the development of prototypes of any kind.

\subsection{Ideas from UI Drawings}

At the beginning of the Talarius project, the children expressed their ideas about the appearance and functionality of the application by drawing UI sketches during their art class. They could choose whether they wanted to draw the game-playing mode or the game editor. Each child created an individual drawing. The rationale for having children make drawings is a wish to allow them to design something new instead of just reacting to existing suggestions [17]. Drawing UI concepts suits the art class context well but there are certain challenges related to their use. Firstly, there is a risk that the children pay a great deal of attention to details while overlooking the bigger picture, that is, what the objects in their drawings do and how they behave [3]. Secondly, despite the assumption that expression by drawing is easy and natural for children, they might have problems, for example, with understanding the idea of drawing things that would be seen on the screen [19]. Some problems did surface in the Talarius project as well. Despite recognizing the gradual development of the Talarius prototype, the children had a hard time picturing a link between this change and their individual ideas. The developers, however, considered the UI drawings to be of great value for their work. They made use of the drawings by analyzing their main attributes and by placing them all on display on the walls of their office in order to be able to continually draw upon them for guidance in design decisions. In problematic situations related to, for example, the choice of colors or layout, it was easy to turn to the drawings for clues and inspiration.

The developers discovered that the UI elements included in the drawings and their locations reflected the children's familiarity with common Windows software. This suggested that the developers could adhere to familiar conventions in order to enhance the learnability and usability of the application, yet without making it too much of a tool and too little of a game. The importance of quick learning is highlighted especially in children's software, as they are often prone to lose their interest unless they get in control of the software rapidly (e.g., [21]). Another navigationrelated issue evident in the pictures was that many tasks were performed using buttons (instead of menus), which suggested that the children wanted all the most essential options to be visible on the screen at all times in order to find them quickly. Figure 1 entails "Quit," "Continue," "Question," and "Information" buttons in the top right hand corner, and buttons for choosing the game piece in the bottom right hand corner.

In the drawings depicting the playing mode, it was observed that it was very important for the children to see quickly what the status of the game and standings of the players were at a given time. The children had very different ways of representing the standings in their pictures but the common element was that this information was clearly visible and multiple formats of presenting the status were often used. In Figure 1, the status of the player is represented

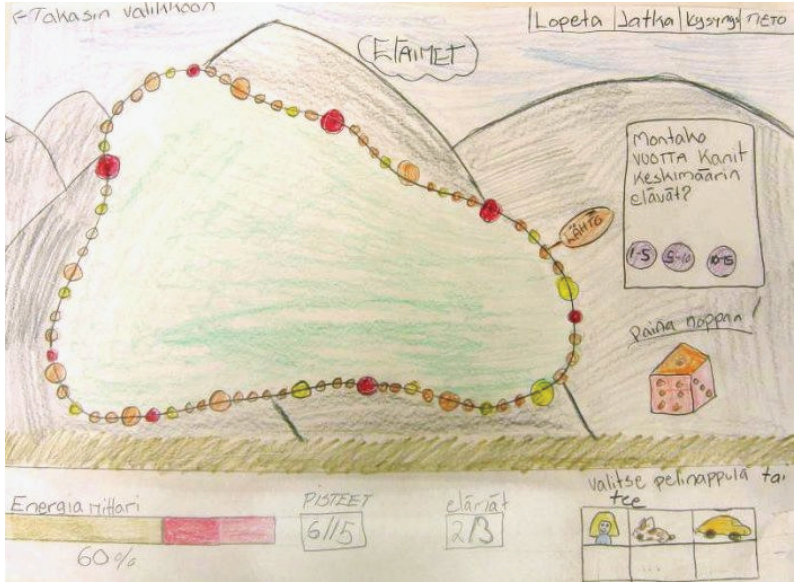

Figure 1: An example of the user interface drawings.

in terms of three different indicators: energy, points, and lives. In the game editor mode, the children's desire for as much freedom of choice as possible became apparent, which is in line with observations made by Druin et al. [21] about children wanting a large variety of functions and something to explore. According to the drawings, the children wanted the software to enable them, for example, to create backgrounds and characters, to choose freely the game path and the shape and color of the squares on it, to adjust the level of difficulty, and to add animations to the game.

\subsection{Issues Discovered with Idea Maps}

As brought up above, the children did not see the link between their individual drawings and the final outcome very well, which decreased their sense of ownership of the ideas. Guha et al. [2] have tackled this problem with a special technique for gradually merging ideas to make the process visible. In the Virtual Peatland project we took a somewhat related approach, attempting to make the different workshop sessions - as well as the activities within a session - build on each other more concretely. The workshops were, for a large part, based on gradual idea map creation.

The collaboration started with a session in which the children and the researchers created idea maps together to chart initial ideas about the content and structure of the site. In this paper, we leave the topic-specific content issues aside and only discuss children's opinions about more general questions, such as the presentation forms to be used in the learning environment. The children first made individual lists of their ideas and, based on them, suggested things to be included in a collective list of ideas. After this, the children suggested which issues on the list they considered the most important, and these were used as the basis for an idea map. Out of the individual lists and the collective list, the children highlighted games, pictures, quizzes, animations, and "learning by seeing and hearing" as the most important presentation forms, and these were taken into further discussion with the aid of the idea map. Similarly as the children in the Talarius project, they emphasized especially 
the importance of being able to create and explore-for example, to make a peatland, which became one of the two main tasks in the Peatland Adventure game-and having a variety of different activities to choose among. Later, in another session, the idea map was taken onto a more detailed and concrete level: the children worked in groups to select specific peatland species they considered the most interesting or important and to pick the most appealing presentation forms among those suggested previously. Another form of idea maps used in this project was a "game idea map" created by a group of children who were especially interested in game-related things. The main observations about their game idea were that their game had a boardgame-like structure and that they wanted various different kinds of subtasks, again a confirmation of the importance of variety and a large selection of things to do.

The suggestions obtained from these activities guided us to include a "from children to children" section in the learning environment, in addition to the Peatland Adventure game, to provide the users with varying activities. The children's section contains quizzes, crossword puzzles, and other types of tasks created by the participant children, video clips filmed during a peatland excursion with the children, and a Talarius-based board game about peatlands. In addition, through these content creation activities, we aimed to provide the children with a possibility to contribute concretely to the outcome and thereby promote their feeling of having an influence in the development of the website. The creation of contents did play an important role in terms of the children's feeling of ownership. Through these very concrete creations and their being straightforwardly present in the final outcome, the children saw more clearly that their participation had yielded something that furthered the development of the application. When comparing the children's experiences from the Talarius and Virtual Peatland projects, the latter succeeded with conveying the feeling of ownership better. When the children were asked whether they felt that their ideas showed in the final outcome, there were more negative than affirmative answers in the Talarius project, while in the Virtual Peatland project it was vice versa. Similarly when asked whether they considered that they had power in the development of the application, the difference between the two projects was noticeable. This was mainly due to the content creation activities which were in a considerably greater role in the Virtual Peatland project. The children felt empowered especially in terms of the quizzes they made. Moreover, in an interview conducted after the Virtual Peatland project, the content creation activities were also the best remembered aspects of the whole process.

\subsection{Obtaining Ideas from Existing Learning Environments}

Critiquing existing applications has proved a successful technique in design projects [19-21]. Having children point out pros and cons about different applications has helped the designers understand children's ways of interacting with technologies, uncover problems, and start developing solutions based on observations about children's preferences [19]. We asked the children to evaluate existing websites both in the Virtual Peatland project and in the Kids' Site project. Some of the websites were thematically related to the topics of the projects, whereas others were chosen merely because they included a variety of different activities and ways of presenting information. The children gave feedback on the websites, telling which features they did or did not like, and what kinds of ideas the websites gave them as regards the learning environment under development.

Consistently with observations made in previous research (e.g., $[15,21])$ and confirming issues discovered with the other techniques in our projects, the children preferred sites which had a large variety of different activities or even a possibility to create something themselves, and it was very important to them what the site looked like. One interesting layout-related observation revealed through this technique in both projects was that having much empty space on a page was a negative thing in the children's opinion. Instead, the children's wish for a great variety of content existed also on single-page level. As the UI drawings also suggested, the desire to have plenty of visible elements concerned navigation as well: the children did not want to move back and forth much, they preferred having as direct access to all the parts of the site as possible.

In regards to the contents of the learning environment, the children wanted excitement and things that were related to real life. Their hope for real-life feel extended also to the visual appearance of the learning environment; the children liked illustrations that used real photographs. Additionally, as regards the illustrations, the children wanted to explore pictures with a great deal of detail, which is consistent with their preference for a variety and a great amount of content in general. The children also liked the idea of one main character that illustrates a learning environment-a game character or alternatively an animated "mascot" that appears on different pages throughout the website.

The children's opinions led us to introduce an animated cat character on Kids' Site to represent different sections of the site and to present the Rights of the Child. Moreover, the children created various different types of quizzes and puzzles for Virtual Peatland (as mentioned above) and Kids' Site to cater for the desire to have a great variety of activities. The real-life context is also represented in different ways in each of the sites: Virtual Peatland contains photographs taken and videos filmed by children, and Kids' Site has stories written by children about their everyday lives and how the Rights of the Child manifest in their lives. Children's possibility for creative participation is guaranteed especially on Kids' Site through several interactive activities involving their contribution to the website content.

\section{Conclusions and Discussion}

The significance of children's participation is divided into the issues related to carrying out collaborative design and research processes with children and those related to the outcomes of the design projects, namely, attributes of 
TABLE 1: Issues discovered in the projects.

\begin{tabular}{lll}
\hline Category & \multicolumn{1}{c}{ Issue } & Source \\
\hline UI/Navigation & Using familiar UI conventions without risking game-likeness & UI drawings \\
& Controls clearly visible at all times & UI drawings \\
& Existing sites & UI drawings \\
\hline UI/Appearance & Cone status and standings clearly visible at all times & Existing sites \\
& Realistic appearance, for example, photographs & Existing sites \\
\hline \multirow{2}{*}{ Content/Theme } & Themes related to real life & Existing sites \\
& Great variety in themes & Existing sites \\
& & Idea maps \\
\hline & Much freedom of choice in functionality to allow exploration & UI drawings \\
& & Idea maps \\
& & Existing sites \\
& & Idea maps \\
& Possibility to create something & Existing sites \\
\hline
\end{tabular}

children's learning environments. In this section, we will discuss these lessons separately.

\subsection{Lessons Learned for Conducting Collaborative Projects with Children}

One of the aims was to study the development processes and the activities they entailed from the perspective of the children and the developers alike. As we have seen above, involving children in the design process revealed and confirmed to the developers several issues that were useful to know when developing a game-based learning environment or a children's website. From the developers' point of view, the children's contribution was important in many aspects. According to the developers, children's ideas can guide the design of the appearance, functionality, and usability of the application. They especially stated that the children's participation helped them make the software more motivating for children. They also felt that the children's participation is valuable in enhancing the developers' understanding of children as technology users in general.

For the children themselves, participation in a real design project provided a chance to learn new things such as teamwork skills, shared decision-making, planning and designing, content-area and technology related knowledge, and activities which varied from their everyday schoolwork. Four areas of learning were identified in the analysis: (1) content area issues, (2) design skills ranging from general ones, such as more methodical ways of carrying out tasks, to more specific ones, such as different planning and design techniques, (3) social skills needed for collaboration in different compositions from pairs and small groups to speaking up before a larger group, and (4) learning skills, such as searching and evaluating information. In previous research, Druin [25] has also discovered learning outcomes in the same vein.

However, when working with school classes, supporting individual children's experience of contribution was a challenge. In the course of the study, we aimed to respond to this problem in two ways, firstly by improving the collaborative workshops through making them build on one another better, and secondly by incorporating concrete content-creation activities in the process. The contentcreation perspective proved to be an important factor in enhancing the children's feeling of ownership: the project in which they were in a larger role was seen as more successful in terms of conveying this feeling, and the content creation activities were considered as the most enjoyable activities.

In summary, a good collaborative design process consists of varying activities in order to, firstly, provide the developers with rich data to draw upon in their implementation solutions and, secondly, maintain the children's interest in the participation process. Ideally, the activities build on each other, forming a logical and clear continuum which enables the children to follow the development of the application and the manifestation of their ideas. Moreover, the inclusion of concrete content creation activities enhances the children's feeling of ownership of the final outcome.

\subsection{Lessons Learned for the Development of Children's Learning Environments}

From the point of view of the development solutions, the issues discovered can be categorized into user interface and content related points. The UI issues comprise those having to do with navigation and those dealing with the appearance of the application, and the content-related issues concern the themes and the functionality of the applications. Table 1 summarizes these observations. We will discuss a few of these points in more detail.

As children want social interaction in technology [15, 21 ], being able to easily compare scores and standings is important to them in order to be able to monitor how they and others are doing. As regards the appearance, the children wanted each page or screen to be rich with content; not so abundant pages appeared to be boring to the children and to 
imply lack of content in the application altogether. Contentwise, our observations suggest similar issues as previous studies have brought up: the children want a great deal of content and functions to explore, and to create something new-or at least tweak and modify some aspects about the application $[15,21]$. The children's preference for layouts using real photographs over those based on drawings might reflect their wish to avoid too "childish" appearances. The same might be true at the content level; themes dealing with real-life events and topics acknowledge children as part of the society, recognizing their interest in the world around them. On the other hand, the idea of a drawn (and perhaps animated) character as a guide on a website or as an avatar in a game is very appealing to them, most likely due to adding a more personal feel to the website or the game.

To summarize, children's desire for quick command of the application they are using manifests in several ways, such as by wanting to have UI elements (be they function buttons, navigation links, or content elements) constantly visible and readily available, and by calling for clear presentation of the status and standings in games. Content-wise, the most essential issue is versatility and richness of content; the children want creative activities, freedom of choice, and a large variety of things to explore and discover-both on the level of the whole application and, interestingly, also in terms of the structures of single pages or views.

\section{Acknowledgments}

Funding for the projects discussed in this paper has been provided by the National Technology Agency of Finland, the State Provincial Office of Western Finland, the European Social Fund, and the Ministry of Social Affairs and Health in Finland. We also wish to thank all the children, school teachers and after-school facility staff, and the developer teams for collaboration.

\section{References}

[1] A. Druin, "The role of children in the design of new technology," Behaviour and Information Technology, vol. 21, no. 2, pp. 1-25, 2002.

[2] M. L. Guha, A. Druin, G. Chipman, J. A. Fails, S. Simms, and A. Farber, "Working with young children as technology design partners," Communications of the ACM, vol. 48, no. 1, pp. 3942, 2005.

[3] M. Scaife and Y. Rogers, "Kids as informants: telling us what we didn't know or confirming what we knew already?" in The Design of Children's Technology, A. Druin, Ed., pp. 27-50, Morgan Kaufmann, San Francisco, Calif, USA, 1999.

[4] D. Schuler and A. Namioka, "Preface," in Participatory Design: Principles and Practices, D. Schuler and A. Namioka, Eds., Lawrence Erlbaum, Hillsdale, NJ, USA, 1993.

[5] A. Bruckman and A. Bandlow, "HCI for kids," in The HumanComputer Interaction Handbook: Fundamentals, Evolving Technologies, and Emerging Applications, J. Jacko and A. Sears, Eds., pp. 428-440, Lawrence Erlbaum, Mahwah, NJ, USA, 2003.

[6] J. Read, "The ABC of CCI (Child Computer Interaction)," Interfaces 62, pp. 8-9, 2005.
[7] J. Good and J. Robertson, "CARSS: a framework for learnercentred design with children," International Journal of Artificial Intelligence in Education, vol. 16, no. 4, pp. 381-413, 2006.

[8] J. A. Rode, M. Stringer, E. F. Toye, A. R. Simpson, and A. F. Blackwell, "Curriculum-focused design," in Proceeding of the 2nd International Conference on Interaction Design and Children (IDC '03), pp. 119-126, Preston, UK, July 2003.

[9] A. Clark and P. Moss, Listening to Young Children: The Mosaic Approach, National Children's Bureau, London, UK, 2001.

[10] R. A. Hart, Children's Participation: The Theory and Practice of Involving Young Citizens in Community Development and Environmental Care, Earthscan, London, UK, 1997.

[11] V. Nesset and A. Large, "Children in the information technology design process: a review of theories and their applications," Library \&amp; Information Science Research, vol. 26, no. 2, pp. 140-161, 2004.

[12] M. Scaife, Y. Rogers, F. Aldrich, and M. Davies, "Designing for or designing with? Informant design for interactive learning environments," in Proceedings of the SIGCHI Conference on Human Factors in Computing Systems (CHI '97), pp. 343-350, Atlanta, Ga, USA, March 1997.

[13] R. Oosterholt, M. Kusano, and G. de Vries, "Interaction design and human factors support in the development of personal communicator for children," in Proceedings of the SIGCHI Conference on Human Factors in Computing Systems (CHI '96), pp. 450-457, Vancouver, Canada, April 1996.

[14] M. Bekker, J. Beusmans, D. Keyson, and P. Lloyd, "KidReporter: a user requirements gathering technique for designing with children," Interacting with Computers, vol. 15, no. 2, pp. 187-202, 2003.

[15] C. Dindler, E. Eriksson, O. S. Iversen, A. Lykke-Olesen, and M. Ludvigssen, "Mission from Mars-a method for exploring user requirements from children in narrative space," in Proceedings of the 4th International Conference on Interaction Design and Children (IDC'05), pp. 40-47, Boulder, Colo, USA, June 2005.

[16] J. Verhaegh, I. Soute, A. Kessels, and P. Markopoulos, "On the design of Camelot, an outdoor game for children," in Proceeding of the 5th International Conference on Interaction Design and Children (IDC '06), pp. 9-16, Tampere, Finland, June 2006.

[17] D. Bilal, "Draw and tell: children as designers of web interfaces," in Proceedings of the 66th Annual Meeting of the American Society for Information Science and Technology (ASIST '03), pp. 135-141, Long Beach, Calif, USA, October 2003.

[18] L. Hall, S. Woods, K. Dautenhahn, and P. Sobreperez, "Using storyboards to guide virtual world design," in Proceeding of the 3rd International Conference on Interaction Design and Children (IDC'04), pp. 125-126, College Park, Md, USA, June 2004.

[19] C. Jones, L. McIver, L. Gibson, and P. Gregor, "Experiences obtained from designing with children," in Proceeding of the 2nd International Conference on Interaction Design and Children (IDC '03), pp. 69-74, Preston, UK, July 2003.

[20] A. Druin, "What children can teach us: developing digital libraries for children with children," Library Quarterly, vol. 75, no. 1, pp. 20-41, 2005.

[21] A. Druin, B. Bederson, A. Boltman, A. Miura, D. KnottsCallahan, and M. Platt, "Children as our technology design partners," in The Design of Children's Technology, A. Druin, Ed., pp. 51-72, Morgan Kaufmann, San Francisco, Calif, USA, 1999. 
[22] R. C. Richey, J. D. Klein, and W. A. Nelson, "Developmental research: studies of instructional design and development," in Handbook of Research for Educational Communications and Technology, D. Jonassen, Ed., pp. 1099-1130, Lawrence Erlbaum, Mahwah, NJ, USA, 2nd edition, 2004.

[23] J. van den Akker, "Principles and methods of development research," in Design Approaches and Tools in Education and Training, J. van den Akker, R. M. Branch, K. Gustafsson, N. Nieveen, and T. Plomp, Eds., pp. 1-14, Kluwer Academic Publishers, Dordrecht, The Netherlands, 1999.

[24] R. K. Yin, Case Study Research: Design and Methods, Sage, Thousand Oaks, Calif, USA, 2nd edition, 1994.

[25] A. Druin, "Cooperative inquiry: developing new technologies for children with children," in Proceedings of the SIGCHI Conference on Human Factors in Computing Systems (CHI '99), pp. 592-599, Pittsburgh, Pa, USA, May 1999. 

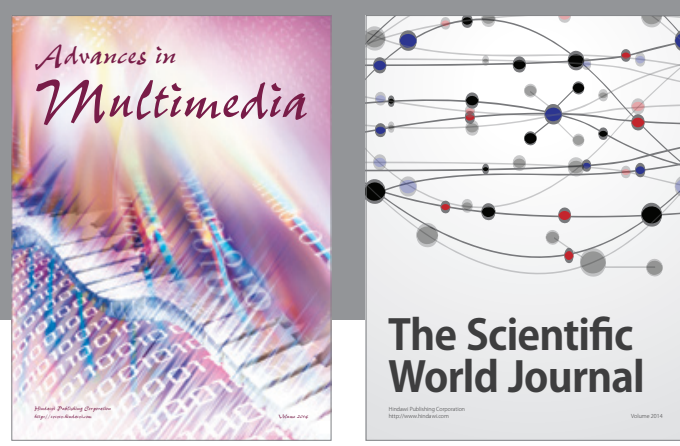

The Scientific World Journal
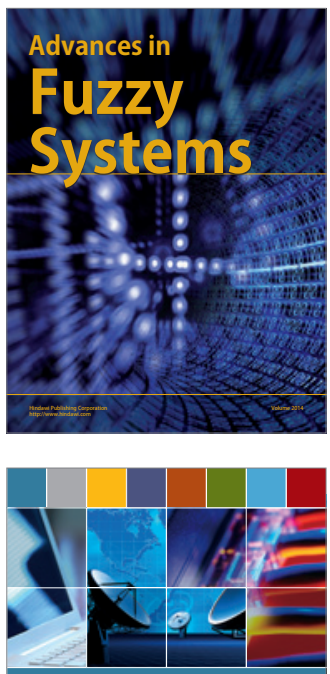

Computer Networks and Communications
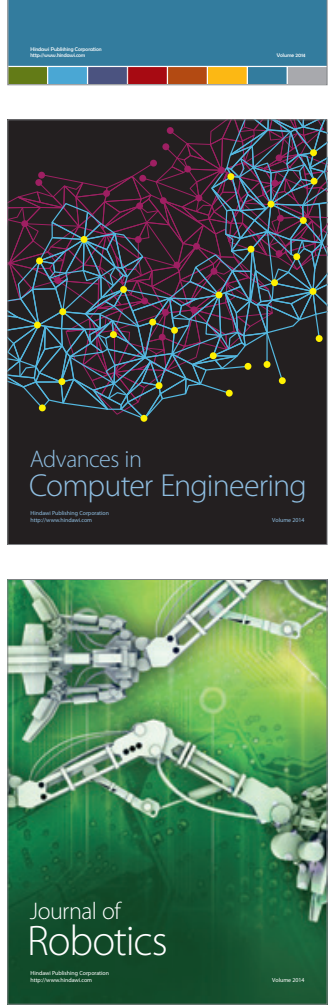
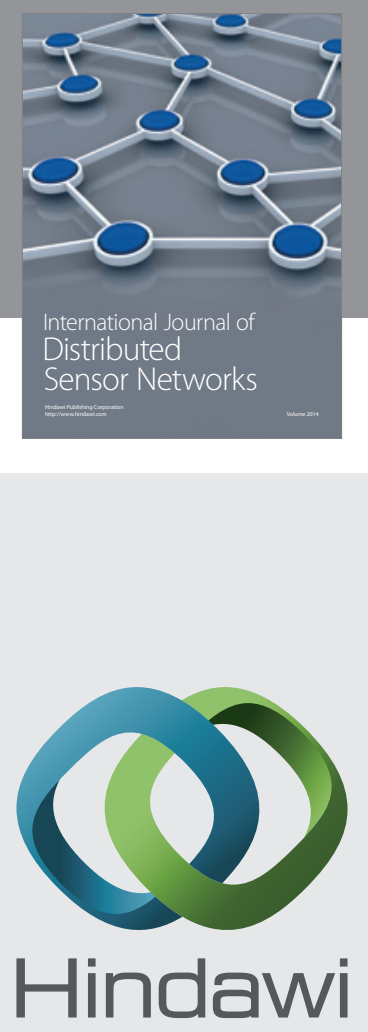

Submit your manuscripts at

http://www.hindawi.com
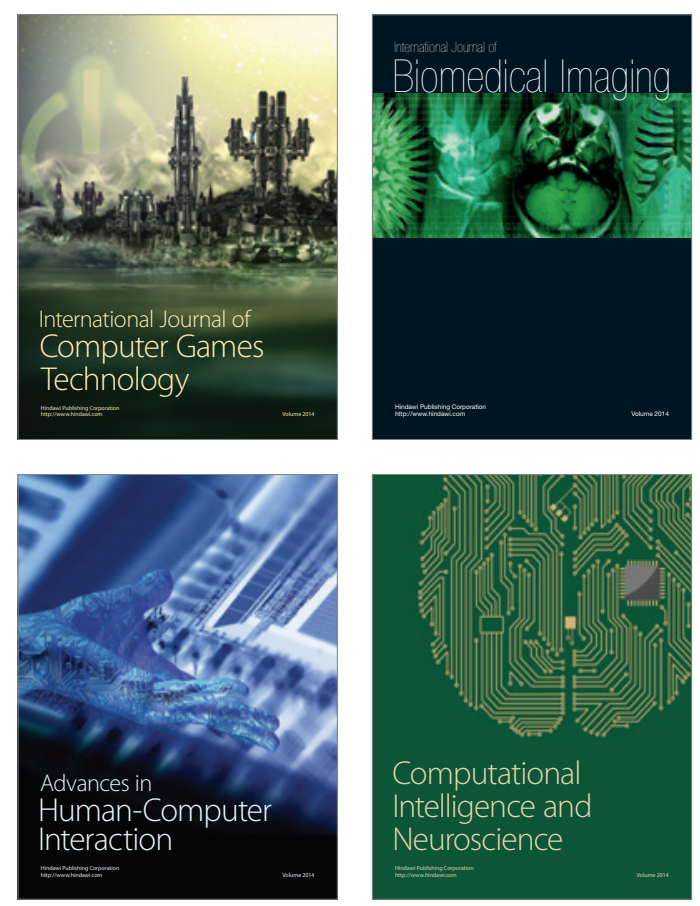
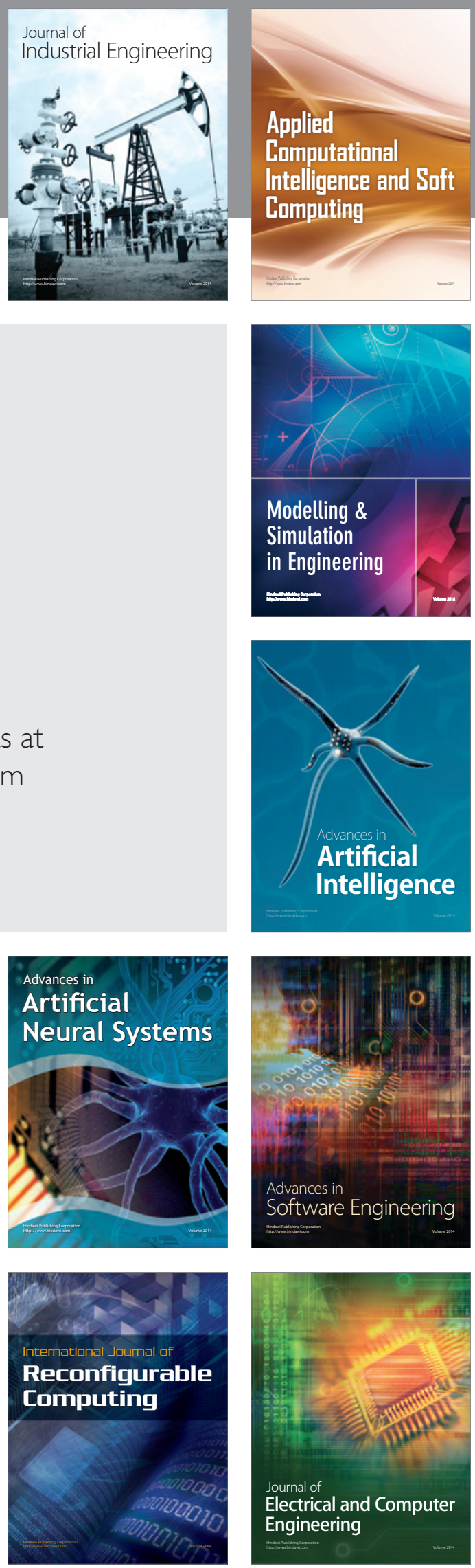